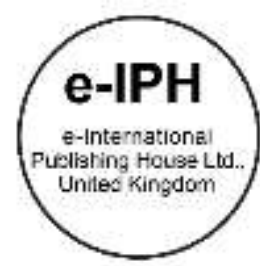

\title{
Perception Factors on Buying Decision between the Thais and Malaysians: Silk authentic and modern usage
}

\author{
Graipop Paspirom¹, Yanin Rugwongwan² \\ ${ }^{1}$ Arch D. Student, Multidisciplinary Design Research Program, \\ ${ }^{2}$ Asst. Prof., Ph.D., \\ Faculty of Architecture, \\ King Mongkut's Institute of Technology Ladkrabang (KMITL) 10520, Thailand \\ Hobbits70@gmail.com
}

\begin{abstract}
The researcher committed searching for the key from cognitive and affective. This study investigates the factors before and after giving information buying decision between Thai and Malaysia with the following objectives: 1 . Study the relevant elements of Thai and Malaysia. 2. To compare and evaluate the interest in Silk authentic and modern usage product 3 . To summarise the results and perceptions that affect form buying.
\end{abstract}

Keywords: Perception, Authentic, Modern Usage, OTOP, Decision

eISSN: 2398-4287 @ 2018. The Authors. Published for AMER ABRA cE-Bs by e-International Publishing House, Ltd., UK. This is an open access article under the CC BYNC-ND license (http://creativecommons.org/licenses/by-nc-nd/4.0/). Peer-review under responsibility of AMER (Association of Malaysian Environment-Behaviour Researchers), ABRA (Association of Behavioural Researchers on Asians) and cE-Bs (Centre for Environment-Behaviour Studies), Faculty of Architecture, Planning \& Surveying, Universiti Teknologi MARA, Malaysia. https://doi.org/10.21834/e-bpj.v3i9.1496

\section{Introduction}

Thai local products or local arts and crafts come from the wisdom that has accumulated for a long time since the ancestors. The necessity for living daily life causes some. The psychological responses to needs cause some. In the past, conventional tools had to be handmade because they were not for sale and they mainly emphasised utilisation. Moreover, local crafts also reflect that the love of arts is not only limited to the cycle of upper-class people in urban areas who live their lives comfortably, but it is also a basic instinct in Thai people of all levels and all regions. Thai peasants can also improve common and daily tools to become objects of art with particular characteristics in each locality (Nion Sanitwong Na Ayutthaya: 2008). Some arts and crafts and local crafts have changed its role from utilisation to become souvenirs, art objects, or household accessories (Graburn, 1976; Schädler, 1979) due to their beauty, and applied for something else. Sometimes, the consumers are those who determine new styles for appropriateness and their usage needs. Therefore, the role of traditional arts and crafts have changed and have led to the loss of some local identities. The changes occur according to the causes and factors, such as the change of materials, users, places, roles, styles, and prices. It can also change by being upgraded or replaced according to the needs of consumers. Nowadays, many arts and crafts have become products that are sold to tourists as souvenirs to remember the country or people that they visited. It is known in the name of tourist art. Later, the name changed to airport art. It is a work that is made to respond to the needs of people from the outside world, not work that is made to return to the needs of oneself for living in a village like it used to be (Saengarun Ratkasikon and Nit Hinchiranan: 2008). Humans have different perceptions, which will affect communication. Moreover, perception is the determiner for behaviours and attitudes. It is a psychological process that responds to a stimulus. Therefore, when the stimulus becomes the determiner for learning,

eISSN: 2398-4287 @ 2018. The Authors. Published for AMER ABRA cE-Bs by e-International Publishing House, Ltd., UK. This is an open access article under the CC BYNC-ND license (http://creativecommons.org/licenses/by-nc-nd/4.0). Peer-review under responsibility of AMER (Association of Malaysian Environment-Behaviour Researchers), ABRA (Association of Behavioural Researchers on Asians) and CE-Bs (Centre for Environment-Behaviour Studies), Faculty of Architecture, Planning \& Surveying, Universiti Teknologi MARA, Malaysia. https://doi.org/10.21834/e-bpj.v3i9.1496 
perception must occur first because it can lead to reasonable interpretation. Hence, perception is the main component for the concept of human attitudes (Phatcharapha Khiaokham: 2003). To bring the products into the target groups, the understanding of arts and crafts and local crafts are not enough.

\subsection{Literature Review}

2.1 Local products: At present, traditional products are developed to be new products to respond to the needs of consumer that are changing due to changes in society and the economy both domestic and international. The roles of some local arts and crafts have changed from utilisation to souvenirs, art objects, or household accessories (Graburn, 1976; Schädler, 1979; Bolabola, 1980). In particular, traditional basketry, pottery, and textiles, including arts and crafts materials are being used with modern work (Wibun Lisuwan, 2003). Many local arts and crafts have become products that are sold to tourists as souvenirs to remember the country or people that they visited. It is known in the name of tourist art. Later, it changed to airport art (Saengarun Ratkasikon and Nit Hinchiranan: 2008). Souvenirs can mean a symbol that is creatively designed to stimulate or emphasise the remembrance of people, incidents, stories, or places. The symbol of many countries is often used to make souvenirs (Aspelin, 1977; Littrell et al., 1994; Anderson \& Littrell, 1995). Souvenirs can also reflect the tradition, identity, creativity, elegance, and feeling of the individual or people that are similar to the traditional arts and crafts (Gordon, 1986; Littrell, 1990).

2.2 Purchasing decision is a method in the consumer purchase decision process. It is a result of the response and stimulus of consumer behaviours from the evaluation of the properties of each brand. The purchasing decision is linked to the learning process; the determination of consumer attitudes in which purchasing intention will be complete when there is an actual purchase; and various forms of marketing promotion to create purchasing decision. The purchasing decision behaviour of consumers is various. Stimulus-response (S-R) is a psychological model that is widely applied to marketing to study the response behaviours of consumers from receiving the marketing stimulus. At the same time, a model called StimulusOrganism-Response (S-O-R) model of consumer behaviour was developed from the S-R model and is also widely used to study the response behaviours of consumers as well. The stimulus is a factor that can be controlled by marketing personnel, designers, or those who are associated with the product. On the other hand, the organism and response from the S-O-R Model are directly controlled by the buyers or the target group for the sale of a product.

2.3 Cultural factor is the study about the impact of cultural diversity towards the purchasing decision. Junyean Moon, Doren Chadee, Surinder Tikoo (2006) mentioned that for individual characteristics, there is only one cultural dimension that affects the purchasing intention. Graburn (1977) and Littrell et al. (1994) stated that different groups of tourists would purchase different souvenirs. Also, the condition of the social, economic, and political aspects are all the factors that affect the purchasing behaviour of the tourists (Ahmed, 1996; Ahn \& Jeong, 1996; and Park, 2000). Likewise, Mary Ann Littrell and Hong Yu (2003, 2005) said that the population factors, such as gender, age, education, and income, are related to the commitment in the expenditure of the tourist. Also, trust in the craft products, such as culture, history, artist, local material, local identity, utilisation, refinement, and beauty value, will create a positive attitude in expenditure and affect the purchasing intention. Consumers from different cultures will have different attitudes and satisfaction.

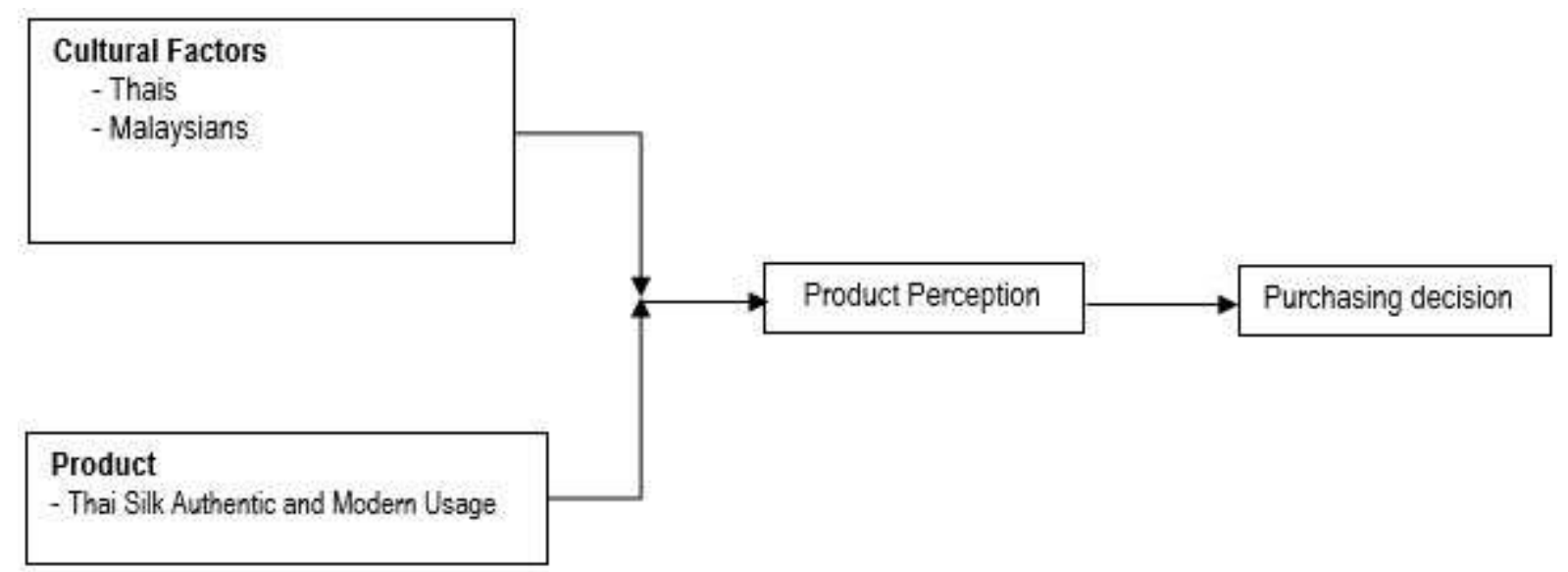

Fig. 1 Research Framework 


\subsection{Methodology}

The study about the perception of the sample towards different design factors was in the form of a rating-scale questionnaire that was made in Thai and translated into English in an identical copy of the questionnaire. Then it was tested with the target group together with pictures of Thai Silk Authentic and Thai Silk Modern Usage with the specific control factors that needed to be studied separately by using the questionnaire. The respondents chose 1 factor from a total of 13 factors from the pictures on the left and the right, which affected the purchasing decision of the sample. The researcher set the scale of the questionnaire to 5 levels in accordance with the Likert Scale as follows: Level-1 score refers to the lowest level of perception and Level-5 score refers to the highest level of perception. The researcher identified the points of Thai silk Authentic and Silk Modern Usage perception as follows: 1. Type of product; 2. Price of Product; 3. Quality of Product; 4. Value of Product; 5. The attractiveness of product; 6. The worthiness of a product; 7.Purchasing decision. Data were collected within the framework

The entire questionnaire for the product groups and responses to the 14 sub-questions was used with the Independent TTest statistical method to test the perception differences among Thais and foreigners of the perception points between letting the sample groups only see the pictures. Additionally, Regression Testing was used to test the factors that affect the demand and purchase decision.

The researcher studied and choose the products' from general information, identity, production process and other relevant information from 5 experts recommend and previous studies. Experts explain local product in Thailand have a lot of but Thai silk have long time of story and silk is a special nation Thai product

\subsection{Discussion and Analysis}

The analysis results of the general information of the 194-person sample group suggests that: the average age was 22 years old; the average income was 22,000 baht per month; the majority had undergraduate degree; $50.5 \%$ were Thais; $49.5 \%$ were Malaysian; $61.3 \%$ were female; and $38.7 \%$ were male. Those in this sample group buy Silk Product from souvenir shops. The most interesting to purchase belongs to Silk products, which accounted for $67.0 \%$. Secondly, unique replica models of each region accounted for $47.9 \%$.

This research emphasised finding the internal feelings of the consumers and perception leading to the purchasing decision towards the type, price, quality, value, attractiveness, worthiness, and purchasing. It was found that the factors that affected perception can lead to a purchasing decision of Thai and Malaysian samples in the aspect of Silk Authentic, which was the value of the product and attractiveness of the product. Also, the factor that affected the perception can affect the purchasing decision of Thai and Malaysian samples in the aspect of Silk Modern Usage, which was the value of the product, the attractiveness of the product, and worthiness of product.

Table 1: Show Different Between Thai and Malaysians

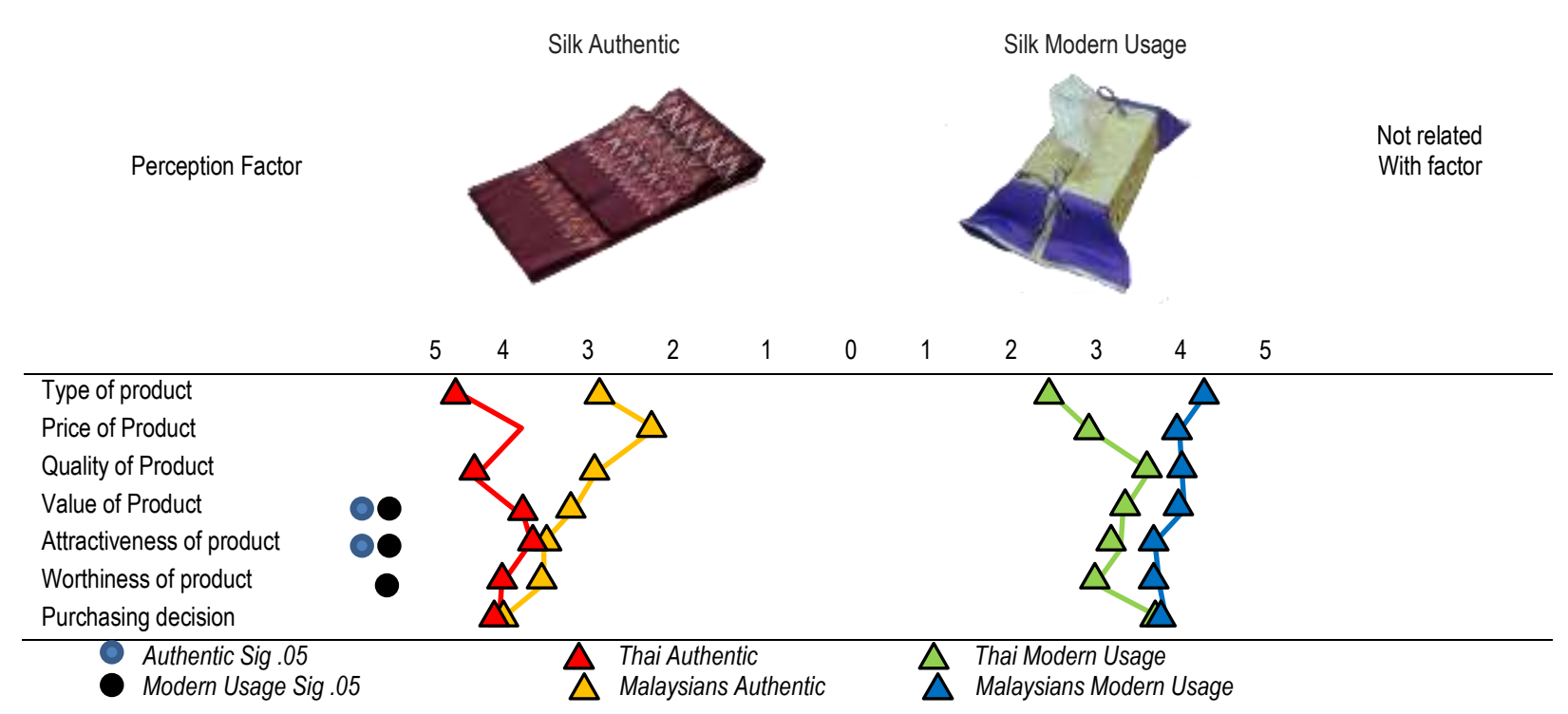

Table 2: Factors that influence buying decisions Silk Authentic

\begin{tabular}{|c|c|c|c|c|}
\hline \multirow{2}{*}{ No. } & \multirow{2}{*}{ Factors that influence buying decisions Thai OTOP Product } & \multicolumn{3}{|c|}{ Silk Authentic } \\
\hline & & B & T-test & Sig. \\
\hline 1 & I Have seen this souvenir before. & .061 & .612 & .540 \\
\hline 2 & I know what this souvenir is about. & -.009 & -.077 & .938 \\
\hline 3 & I know this souvenir's history and usage. & .003 & .043 & .967 \\
\hline 4 & It expresses high cultural value. & -.045 & -.311 & .756 \\
\hline 5 & It possesses highly uniqueness. & .005 & .037 & .973 \\
\hline 6 & It illustrates the high quality of craft skills. & -.361 & -2.642 & .009 \\
\hline
\end{tabular}


- $\quad$ statistical significance .05

For Silk Authentic, it was found that all independent variables jointly explained the variance of the purchase decision at .05 statistical significance level (Sig. value <.05). The multiple correlation value $(\mathrm{R})$ was .760 and the Coefficient of Determination $\left(R^{2}\right)$ was .577, which shows that the independent variables can explain the variance of the dependent variables by $57.7 \%$. When the individual factors were analyzed, it was found that the point in Clause (6), which was fine crafts, had a negative effect on the explanation of the purchase decision at the .05 statistical significance level. While for Clause (8), a product with functional value, and (13), an interesting product, they were factors that had a positive effect on the change of purchase decision at the .05 statistical significance level.

Table 3: Factors that influence buying decisions Silk Modern Usage

\begin{tabular}{|c|c|c|c|c|}
\hline \multirow{2}{*}{ No. } & \multirow{2}{*}{ Factors that influence buying decisions Thai OTOP Product } & \multicolumn{3}{|c|}{ Silk Modern Usage } \\
\hline & & B & T-test & Sig. \\
\hline 1 & I Have seen this souvenir before. & -.170 & -2.391 & .018 \\
\hline 2 & I know what this souvenir is about. & .065 & .836 & .404 \\
\hline 3 & I know this souvenir's history and usage. & .097 & 1.892 & .060 \\
\hline 4 & It expresses high cultural value. & .083 & .954 & .341 \\
\hline 5 & It possesses highly uniqueness. & .084 & .816 & .415 \\
\hline 6 & It illustrates the high quality of craft skills. & -.115 & -1.305 & .194 \\
\hline 7 & It illustrates the high value of aesthetic. & .205 & 2.456 & .015 \\
\hline 8 & It shows high functional value. & 0.65 & .895 & .372 \\
\hline 9 & It shows the quality of rareness. & -.052 & -.901 & .369 \\
\hline 10 & It is qualified as a precious souvenir. & .081 & 1.122 & .263 \\
\hline 11 & It is appropriate to be given as a gift. & .040 & .642 & .522 \\
\hline 12 & It is worth the value of collectible. & .200 & 3.342 & .001 \\
\hline 13 & It is attractive and interesting. & .400 & 5.867 & .000 \\
\hline
\end{tabular}

- $\quad$ statistical significance .05

For Silk Modern Usage, it was found that all independent variables jointly explained the variance of the purchase decision at the .05 statistical significance level (Sig. value < .05). The multiple correlation value $(R)$ was .858 and the Coefficient of Determination $\left(R^{2}\right)$ was .736, which shows that the independent variables can explain the variance of the dependent variables by $73.6 \%$. When the individual factors were analyzed, it was found that the point in Clause (1), visual recognition, was the only one with a negative effect on the explanation of the purchase decision at the .05 statistical significance level. While for Clause (7), products with precious beauty, (12), products with suitability for collectable keepsakes, and (13), interesting products, they were factors that positively affected changes in the purchase decision at the .05 statistical significance level.

\subsection{Conclusions and Recommendations}

From the study on the cultural differences of the consumers and the value perception of authentic and modern styles, it was found that consumers with different cultures, Thai and Malaysian, have a different value perception of authentic and modern products. Thai consumers were familiar with the authentic products, which can be seen from the average that was quite high. Moreover, Thai consumers knew the background, including the cultural representation of those products. They can also perceive the uniqueness and the fineness that represented the aesthetic value, including the utilisation of the products. There were some particular things that Thai consumers could see that made the products rare and suitable for being a present and a collection. Most of them were interesting and worthy to purchase. However, when considering the value perception of modern products, it was found that Thai consumers had a lower value perception than Malaysians in many aspects, such as they had seen the products before and knew about the products.

When considering product perception, Malaysian consumers were not familiar with authentic products, whether the aspect of having seen them before, knowledge, knowledge about the background, cultural representation, uniqueness, fineness, and aesthetic value. On the other hand, in the aspects of utilization value, rare, preciousness, suitable for being a present or a collection, exciting, and worthy to purchase, it was found that Malaysian consumers had a higher perception in such aspects than Thai consumers. However, the exciting thing was that the Thai people had a better perception of authentic products than Malaysians. However, with modern products, Malaysians had a better perception than Thais. This phenomenon can be explained that Thai consumers are more familiar with authentic products because the products can be frequently found in the 
surrounding environment, which is different from modern products that are sold in tourist attractions where foreigners will see those products more often and perceive that those products are representative of local Thai products.

From the above, it is following prior research in many aspects. Guadalupe Revilla and Tim H. Dodd (2003) mentioned that for the perception of authentic souvenirs, domestic tourists often see true authenticity through the appearances and advantages; whereas, foreign tourists often put more weight on the origin or the manufacturing place of the souvenirs. Tourists can perceive the true genuineness of the souvenirs through identity and authenticity, which have fine craftsmanship and are created by members in the locality that reflects the culture and history and are decorated with antique patterns (Littrell, Anderson, and Brown: 1993 and Cohen: 1988).

\section{References}

Aaker, J. L. (2000). "Accessibility or Diagnosticity ? Disentangling the Influence of Culture on Persuasion Processes and Attitudes." J Consum Res 26 (4); $340-57$.

Ampuero,O \& Vila,N.(2006). Consumer perceptions of product packaging. Journal of Consumer Marketing23/2 (2006) 100-112 p; Emerald Group Publishing Limited.

Basu, K. 1995. "Marketing Developing Society Crafts: A Framework for Analysis and Change." In Marketing in a Multicultural World, edited by J. Costa and B. Bamossy, 257-98. Thousand Oaks: Sage Publications.

G.Schiffman,L \& Kanuk,L.(2000). Consumer Behavior. (2 nd ed.). New Jersey: Prentice-hall, INC.

Grote,L \& Wang,D.(1954). Architectural research methods. New York:Print in the United states of America.

Gon P,Calves, Ricardo,(2008). Consumer Behavior: Product Characteristics and Quality Perception.http://mpra.ub.uni- muenchen.de/11142.

M.Meyers, H. \& J.Lubliner, M. (1998). Marketer's guide to successful package design. Illinois: NTC Business books

Robert, G. Hershberger. (1970). "Architecture and Meaning." Journal of Aesthetic Education, Special Issue: The Environment and the Aesthetic Quality of Life 4 (4); 37-55.

Sangarun, Ratakasikorn and Nij Hinchiranan. (2008). Laksana Thai (Thai Characters).Bangkok: Amarin Printing \& Publishing.

Sarath, Simsiri. (2010). Factors Affecting Buyers. Perceptions in Accordance with Marketing Strategy: A Case of Vernacular Thai Product. Social and Behavioral Sciences 5; 1283-7.

Sommer, B\&R.( 1997). A practical guide to behavioral research tools and techniques. (4 th ed.). New york: Oxford university press.

Schiffman, Leon G. and Kanuk Leslie Lazar. (1991). Consumer Behavior. 4 th.ed. New Jersey: Englewood Cliffs.

Siriwan and Team. (1998). Newbusiness management. bangkok: Teera Film and Saitext Co.,Ltd

Tanyamai chiarakul. (2014).The Problems and the Adaptation of OTOP to AEC. Business Executive Journal 1; 180 -181

Takada, H, and D. Jain. 1991. "Cross-National Analysis of Diffusion of Consumer Durable Goods in Pacific Rim Countries." J Mark 55 (2); $48-54$.

Viboon, Leesuwan. (2003). Folk Art. Bangkok: Amarin Printing \& Publishing.

Viboon, Leesuwan. (2010). Folk Handicrafts: Local Identity. Silpakorn University International Journal.

Wallschlaeger,C. \& Busic-Snyder,C.(1992).Basic visual concepts and principles for artists, architects, and designers. United States of America: McGraw Hill companies. Noel, H.(2009). Consumer behavior. Lausanne 6. AVA Publishing SA.

Yuri Lee, So Young Kim, Yoo-Kyoung Seock, Yunjin Cho. 2009. "Tourists' Attitudes Towards Textiles and Apparel-Related Cultural Products: A Cross-Cultural Marketing Study." Tourism Management 30; 724-32. 